\title{
In memoriam Prof. Erik Boijsen
}

\author{
Olle Ekberg $^{1}$ (D) $\cdot$ Peter Aspelin $^{1} \cdot$ Stanley Baum $^{1}$
}

Received: 17 October 2017 / Accepted: 17 October 2017 / Published online: 16 November 2017

(C) European Society of Radiology 2017

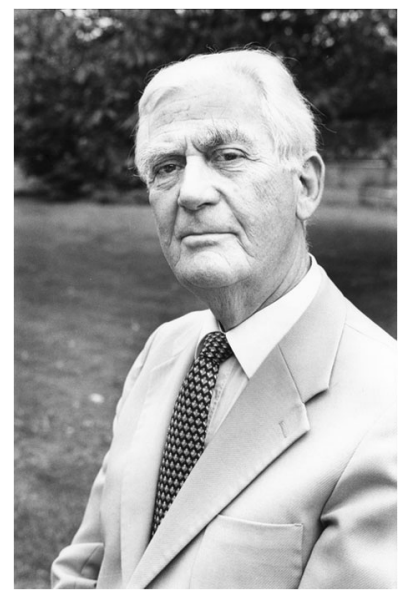

\section{In Memoriam}

Dr Erik Boijsen died peacefully in Lund, Sweden, on 27 June 2017 at the age of 95 . He was a driving force in the development of angiography and interventional radiology, a visionary educator and a pioneer in new procedures.

Dr Boijsen grew up on a big farm outside Lund. Part of the land is now a scenic recreational area. He entered medical school at Lund University and graduated in 1949. Initially Erik wished to go into general practice but he wanted first to know more about radiology, and never left our fascinating

Olle Ekberg

olle.ekberg@med.lu.se

1 Lund University, Department of Translational Medicine, Division of Medical Radiology, Skåne University Hospital, Inga Marie Nilssons gata 49, SE-205 02 Malmö, Sweden specialty. He received his $\mathrm{PhD}$ on a dissertation on the vascular anatomy of the kidneys. He was Visiting Professor at Stanford, California, in 1962. He quickly rose through the academic ranks and became a full professor at Lund University in 1970, first at Malmö General Hospital and later at the hospital in Lund. Erik created an outstanding intellectual environment at these two departments. Erik personally developed angiography and interventional radiology. He introduced pharmacoangiography in the thorax and abdomen. Numerous radiologists from all over the world made pilgrimage to Lund and Malmö and became leading radiologists in their home countries. When we got to know Erik he was already a giant in angiography with a large national and international network. Even when he was chairman, Erik took part in day-today work. He personalized the most sophisticated diagnosis. Angiography was for some years the panacea everybody hoped for. Erik had a great presence and was at the same time perceptive, with a capacity to mediate scientific depth even to trivial questions and make spurious things understandable. He always had answers to questions from younger colleagues. If he did not have the answer, he would say "find out!" He was both curious and demanding. He intermingled clinical routine with research and development. Such a cadence is often lacking today. Erik was a visionary educator, and at all seven universities in Sweden there has been a professor that was educated by him. Therefore his greatest legacy is the generation of trainees who learned from him including residents and fellows, some of whom have become outstanding academic radiologists at prestigious medical centres across the world. Erik also introduced several new and pioneering techniques after angiography: ultrasound, CT and MRI. He served in leadership positions in national and international radiology organizations. For 10 years he was Editor-in-Chief for Acta Radiologica. He was an honorary member of the Radiological Society of North America and he got the European Congress 
of Radiology Gold Medal. He was an honorary member of the Swedish as well as the Nordic Society of Medical Radiology. As an accomplished author Erik wrote more than 150 scientific papers within different fields of diagnostic radiology. As a consequence of his research some $25 \mathrm{PhD}$ dissertations have appeared in Lund and Malmö.

Erik loved his work. His way of relaxing was working at his country house building traditional stone fences, walking in the surrounding nature and, when he was younger, hunting. He loved classical music and was very interested in history. Erik had a straightforward and ingenious manner. With both an imposing personality and in- tegrity he was a radiological aristocrat. When Erik was in the room he was the central figure. He was the giant on whose shoulders we stood. He provided encouragement and friendship and gave us time and possibility to do research and to develop. He fostered us and then paved the way for our professional careers.

An emblematic radiologist who continuously inspired and stimulated us has passed away.

He is survived by his two children, Marianne and Göran, with five grandchildren and five great-grandchildren.

Olle Ekberg, Peter Aspelin and Stanley Baum 